\title{
Let's get DC right before it's too late
}

Received: 25th June, 2001

\section{Ros Altmann}

is an investment banker with 18 years' involvement in pension fund management. She has a PhD in Economics from the London School of Economics and Political Science (LSE). She worked for the Treasury as a consultant to the Myners Review of Institutional Investment and is involved in pensions, retirement, savings and investment policy work. She is a member of the Securities Institute and the Institute of Directors, and a Governor of LSE.

\begin{abstract}
The trend towards defined contribution (DC) pension provision in the UK is likely to accelerate in coming years. At the moment, trustees of DC schemes, their consultants and their members are not generally making best use of DC arrangements. Contribution levels are inadequate, investment options are not well-designed for the purpose, and DC pensions are, on current trends, likely to prove inadequate to support future retirees. In theory, DC schemes transfer investment risk to the individual; but, in practice, the ultimate risk lies with the state. The taxpayer will end up having to support many more people in retirement. Therefore, the industry urgently needs to address the issues relating to advice on contributions (and perhaps lengthening working life to allow sufficient sums to be paid in) and structuring suitable investment options (and improving financial education to enable people to understand how best to provide for themselves). Getting DC pension schemes working better will be to the benefit of us all.
\end{abstract}

Keywords: defined contribution; DB; investment options; trustee responsibility; Myners; retirement

\section{Introduction}

The UK defined contribution (DC) occupational pension provision is still in its infancy. It is expected that the trend to DC provision will accelerate as pension fund surpluses decline, as maturity profiles of schemes age, as mortality continues to improve, as firms seek to gain more control over their costs, and as the effects of regulatory changes continue to bite.

The way it is currently structured, DC pension provision is not working well in

Tel: +44 (0)20 8343 0055; Fax: +44 (0)20 8349 3744; e-mail: ros.altmann@genesys.net the UK. Responsibilities and requirements of trustees and members are not yet well recognised or well understood. There is currently substantial information asymmetry in DC pension provision, with those involved not being offered sufficient information, education or guidance as regards the contributions they need to make, investment policies or options they should be considering, or annuities to buy at the end. Survey evidence suggests that people think they will be able to achieve a reasonable level of income in retirement from their DC pension plan, but they have not been shown how to plan the pension and retirement process properly in order to meet these expectations. As the authorities encourage more individual responsibility for pension provision, it is essential that we try to ensure the DC system will provide decent pensions and prevent large numbers of people falling 


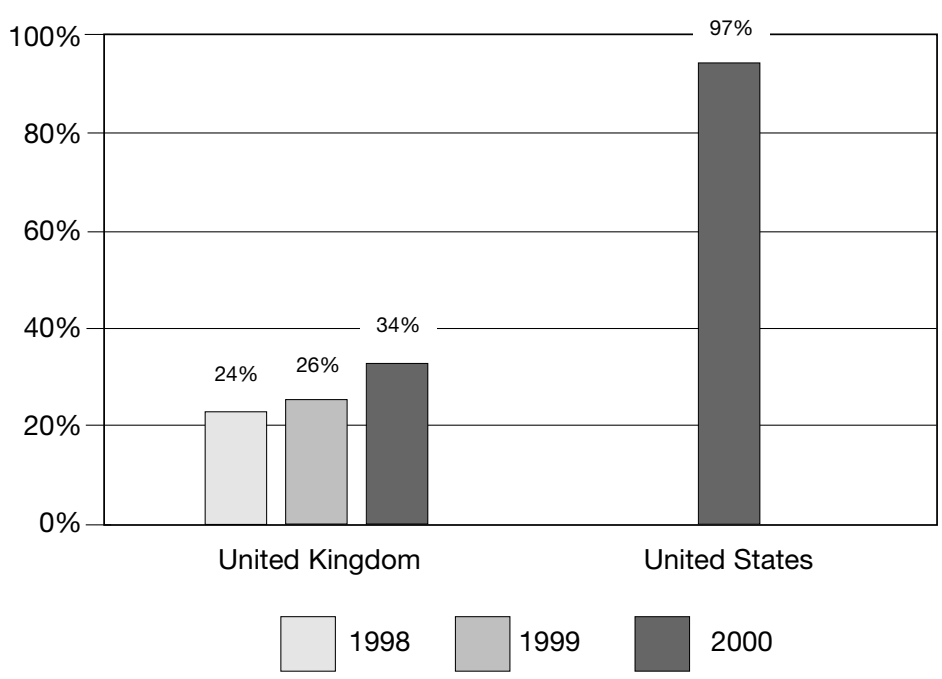

Figure 1: Percentage of companies now using a DC plan

back on means-tested support in retirement. ${ }^{1}$

This paper discusses some of the more important issues involved in trying to improve the DC pension system in the UK. More information is required to explain to people what level of contributions they need to make. More attention is required to structuring investment options, default options and even lifestyling options, to better meet members' differing needs and risk tolerances. More guidance is required for trustees as to what options to provide. It is urgent to tackle these issues now, in order to give DC members a better chance of providing a decent pension (thus preventing large numbers falling back on means-tested support in retirement) and also to prevent trustees unwittingly failing in their responsibility to safeguard the pension assets of their members. Finally, this debate highlights the urgent need to provide better financial education more widely.

\section{Prevalence of DC}

There has been much written of the trend away from defined benefit (DB) pension provision and towards DC arrangements. The evidence has mounted recently, showing occupational schemes increasingly deciding to close their DB schemes to new members, or wind them up and open DC schemes for new employees.

The trend to DC is advancing but is still in its early stages, with only about a third of schemes in the UK being DC, whereas in the USA, the figure is 97 per cent (see Figure 1). Table 1 shows that the proportion of DC schemes is rising and it is, therefore, imperative that the current problems of DC pension provision are addressed as soon as possible, The Myners Review ${ }^{2}$ did look at this topic, but there are still significant challenges ahead here. Table 1 also shows that DC is much more prevalent among small schemes (but the numbers of large schemes switching to DC recently has accelerated).

In fact it is striking that there are no comprehensive UK data on the size of assets in DC arrangements, or their investment profile. This is partly because most DC schemes are in small companies and they are immature, so the proportion of assets is much lower than one third, 
Table 1: Trends in UK defined contribution pension fund provision

\begin{tabular}{|c|c|c|c|c|c|c|c|c|c|}
\hline & \multicolumn{3}{|c|}{ DC schemes } & \multicolumn{3}{|c|}{ DB schemes } & \multicolumn{3}{|c|}{ Hybrid schemes } \\
\hline & 1994 & 1998 & 1999 & 1994 & 1998 & 1999 & 1994 & 1998 & 1999 \\
\hline Total schemes in survey & 55 & 86 & 79 & 703 & 562 & 519 & 43 & 56 & 56 \\
\hline$\%$ of total & 6.9 & 12.2 & 12.1 & 87.8 & 79.8 & 79.3 & 5.4 & 8.0 & 8.6 \\
\hline $\begin{array}{l}\text { Schemes in survey } \\
<250 \text { members }\end{array}$ & 29 & 36 & 33 & 134 & 120 & 96 & 5 & 10 & 6 \\
\hline$\%$ of small schemes & 17.3 & 21.7 & 24.4 & 79.8 & 72.3 & 71.1 & 3.0 & 6.0 & 4.4 \\
\hline $\begin{array}{l}\text { Schemes in survey } \\
>5,000 \text { members }\end{array}$ & 3 & 4 & 6 & 142 & 110 & 112 & 9 & 15 & 16 \\
\hline$\%$ of large schemes & 1.9 & 3.1 & 4.5 & 92.0 & 85.3 & 83.6 & 5.8 & 11.6 & 11.9 \\
\hline
\end{tabular}

Source: NAPF Annual Surveys ${ }^{3}$

thus the data gatherers have not deemed it important to focus on this 'minority' area of the pensions arena. Nevertheless, the Myners Review rightly recommends that more data are urgently required, and it is hoped that the industry will take up the challenge quickly to provide more complete information.

\section{Why are employers moving away from DB?}

DB schemes are suffering from several negative influences. Increased longevity, demographic trends and earlier retirement imply a longer period of retirement and much more expensive pension provision. Many schemes have become so large that they are dwarfing the size of their sponsor companies and, as they mature, contribution holidays are coming to an end. Changes in the regulatory environment in recent years (Limited Price Indexation (LPI), taxation of surpluses, removal of Advance Corporation Tax (ACT) relief and even the soon-to-be-removed Minimum Funding Requirement (MFR)) have increased the complexity and compliance costs of running DB schemes. Finally, even though the MFR will be removed, there is another recent regulatory change which could be more damaging to DB provision; this is the introduction of the new accounting standard FRS17. Many corporate boards will be reluctant to have the volatility of pension fund gains and losses affecting their balance sheets. The Accounting Standards Board has introduced this new measure to require companies to report gains and losses on pension fund assets every year in a 'Statement of Recognised Gains and Losses' (STRGL) which is attached to the balance sheet. This reporting standard has to be implemented by 2003 and will mean that the volatility of DB asset values can no longer be smoothed away as in the past. This is likely to be used by analysts and could directly affect corporate valuations on an annual basis. Given all these negative factors, employers are bound to be attracted to DC.

There is, thus, significant evidence to suggest that the move away from $\mathrm{DB}$ is inevitable and the only question is: how fast it will happen?

\section{Advantages and disadvantages of DC}

In DC schemes, the risk of inadequate income in retirement and investment shortfalls rests with the individual, rather than a company as in DB, but ultimately, of course, the final risk lies with the state. If occupational pensions are inadequate, the elderly will fall back on means-tested income support. Therefore, it is in the interest of society as a whole 
to ensure that DC pensions turn out to be adequate.

Although in the past DB schemes have always provided better pensions for members than DC, this does not have to be the case. There could, in fact, be potential advantages of DC provision if it can be structured correctly. Members should, in theory, benefit from

— portability;

- more control over their investments;

- more flexibility over retirement age; and

- could even have rate of return or benefit guarantees. ${ }^{4,5}$

However, the way it is provided at the moment in the UK is certainly not optimal. Much could be done to improve the pensions provided by DC arrangements.

Although members are not benefiting from the potential advantages of DC, there is evidence that employers are able to enjoy several advantages when providing a DC rather than a DB scheme. These include:

- more certainty of and control over costs of pension provision (with no promised level of pension by the employer and therefore no need to be concerned about any shortfall in funds);

- fewer problems of compliance with regulations (no need to worry about LPI, MFR, FRS17 etc);

- increased visibility of contributions to employees (with employers able to show exactly how much they are contributing);

- ability to offer more flexible benefits packages (with employers claiming they are giving workers the choice to structure their own preferred type of benefit, for example, exchanging lower pension contributions for higher salary, health cover etc); and perhaps crucially — the opportunity for the employer to

- reduce costs by lowering contributions.

UK schemes are not nearly as well-developed as those in the USA, and members of DC schemes here suffer several disadvantages. These include

- lower employer contributions meaning less put aside to provide the pension;

— lack of well-designed investment options;

- no employer to make up any investment shortfall;

- poor annuity rates at the point of final pension conversion.

However, from an employer's point of view there are not really many disadvantages of switching to DC, other than perhaps the actual inconvenience of setting up and administering a new scheme.

\section{Key issues to be addressed}

So what are the key issues, which need to be addressed appropriately, if DC pensions are not going to cause major disappointment and problems in years to come?

There are three crucial elements which will determine the adequacy of DC pensions.

1 Level of contributions;

2 Investment performance - net of fees;

3 Cost of annuities chosen to buy the pension.

Annuities will not be specifically dealt with here, as this is a large topic and was not really covered by the Myners Review. 
Per cent of members of non-contributory schemes with employers contributions above $6 \%$ of salary

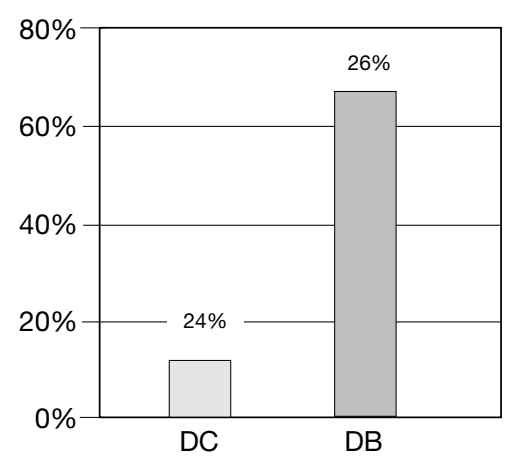

Source: NAPF Annual Survey 1999

Figure 2: Contributions

As regards contributions, the Government urgently needs to investigate the level of employer contributions. They are simply too low.

National Association of Pension Fund (NAPF) Survey evidence for 1999 shows (see Figure 2) that, for non-contributory DC schemes, about one-tenth of employers contribute more than 6 per cent of salary, compared with over three-quarters in DB, and the average employer's contribution level in contributory schemes is only 5.8 per cent in DC, but 10.1 per cent in DB. A very recent example is that of $\mathrm{BT}$, who recently announced the closure of their DB scheme to new members and a new DC scheme to be set up for new employees. The Financial Times estimated that the contribution level would fall from 9.5 per cent of salary to only 6 per cent of salary in the new scheme, with significant savings for BT.

These contribution rates are far too low and suggest that DC schemes will not provide adequate pensions. In fact, a study by Blake, ${ }^{6}$ reported in the Economic Journal 2000, estimated the contribution rates needed to provide a pension of two-thirds final salary.

These assume: a male retiring at age
Average \% contribution rate from employers for contributory schemes

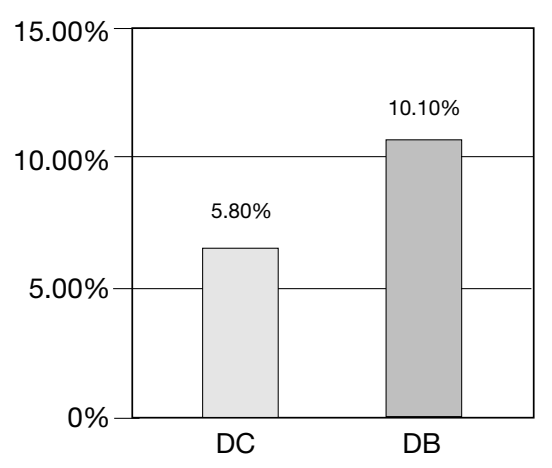

65 , with no previous contributions into any other scheme; salary increases of 3 per cent per annum; and investment returns of 6 per cent per annum.

These results demonstrate that contribution levels of 6 per cent are nowhere near sufficient. In fact, Blake's estimates of the pension contributions needed suggest that, if starting at older ages, no-one is likely to be able to put enough into their fund to earn a two-thirds pension, because the contributions required after age 40 are higher than the maximum permitted by the current legislation.

Of course, even if contributions are sufficient, it is also essential that the monies are invested effectively. Investment performance is another major issue.

In $\mathrm{DB}$, investment performance will affect the security of the pension, but in DC, investment performance will affect the amount of pension.

So, for occupational schemes where trustees make the investment decisions, the trustees' investment expertise is, arguably, even more important in DC than in DB. And many schemes (including stakeholders) rely on individuals to choose their own investment allocation. If the Myners 
Table 2: Contributions needed to achieve a pension of two-thirds of final salary

\begin{tabular}{lll}
\hline $\begin{array}{l}\text { Age at commencement } \\
\text { of contributions (male) }\end{array}$ & $\begin{array}{l}\text { Required contributions } \\
\text { (\% of salary) }\end{array}$ & $\begin{array}{l}\text { Maximum contributions } \\
\text { permitted by current } \\
\text { legislation (\% of salary) }\end{array}$ \\
\hline 25 & 10.9 & 129.8 \\
30 & 13.4 & 17.5 \\
35 & 16.8 & 17.5 \\
40 & 21.7 & 20 \\
45 & 28.9 & 20 \\
50 & 40.8 & 25 \\
55 & 64.1 & 30 \\
60 & & 35 \\
\hline
\end{tabular}

Source: Economic Journal ${ }^{6}$

Review questioned whether pension fund trustees could adequately understand investment issues, even with the help of professional advisers, how can ordinary DC scheme members, without advice, be expected to address the investment issues properly? ${ }^{7}$

They need education and guidance, perhaps with the authorities issuing 'Best Practice' guidelines for trustees and members. A useful starting point may be to introduce measures modelled on the US 'Safe Harbour' guidelines. Trustees of DC schemes may face potential claims against them in the future if their choices of investment products or investment managers are deemed to have been poor. The net investment performance is a critical factor in determining the size of final pension and providers or trustees need to ensure that they offer sufficient choice of products for members to construct a reasonably well-diversified portfolio, if they so wish. If future pensioners suffer as a result of inadequate options available, or even as a result of charges which are too high and detract from investment growth, they may be able to claim that trustees should have offered better alternatives.

The US Safe Harbour regulations basically require a DC plan to offer the following:

— at least three investment alternatives;
- each of these must be diversified, with different risk/return characteristics;

- members must be able to control the assets and change investment choices;

- members must receive good information;

— investment choices must allow creation of an appropriate portfolio;

- the combination of choices should allow portfolio risk minimisation through diversification.

As long as they meet these requirements, US trustees cannot be sued for investment negligence. Guidance of this sort would be very useful here.

At the moment, many UK schemes certainly do not meet these criteria. In some schemes, trustees offer no choice of investment, just one product. The Watson Wyatt 2000 Pension Plan Design Survey $^{8}$ showed that 23 per cent of DC schemes offered no investment choice at all - even though it is the member who bears the investment risk. This is inadequate.

There is an urgent need to develop a range of suitable investment products specifically for DC. These products should provide for differing risk, asset and time horizon requirements and should surely include passive as well as active options, to allow capture of the full market movement of an asset class, if 
desired. Alternative assets, such as venture capital, hedge funds and even socially responsible investment vehicles could also be included in the form of investment trusts, for example.

Also, for those who do not feel able to take their own decisions, there should be well-developed default options. Over 75 per cent of DC members use their scheme's default option, but in some schemes this is just a 'balanced fund', measured against the peer group benchmark of DB schemes. This is not really suitable. Other schemes offer 'lifestyling' options, whereby the fund is switched increasingly into bonds in the years before retirement age. This, too, is often an inappropriate investment strategy and takes no account of increased longevity, different risk preferences, other assets held by the members, or whether they are going to switch into drawdown on retirement and therefore go back from bonds to equities as soon as they retire.

There is, certainly, a role for trustee and member education to explain the investment strategies which are most appropriate to different individuals' circumstances. Just as we may recommend that a DB scheme should have an individually tailored benchmark which will vary according to its liability profile, so we could also recommend an approach of tailored investment products to be offered to DC scheme members who want good 'default' options, varying according to their circumstances. These could include such elements as age, family circumstances, risk appetite, alternative assets, etc. One can conceive of a range of DC pension products being offered to members in categories such as 'youth', 'middle years', 'pre-retirement', 'single', 'married', 'high risk', 'pure equity', etc. These are just examples, but a whole structured programme, made up of units of different products, could be devised by the offering companies or the trustees.

The trustees have a large responsibility in choosing which investment provider should manage the assets on behalf of members. It would be useful to offer guidance as to what they should look for when making this choice. The academic evidence suggests, for example, that the factor most frequently focused on - past performance - does not offer the best guide. Past performance is not a reliable predictor of future performance. Several other factors could be suggested which might be of greater benefit to members of DC schemes. These would include:

- the availability and quality of advice provided to members (standard of informational material, risk modellers, individual financial counselling etc);

— the breadth of their investment products range;

- the level of charges (high charges have a significant detrimental effect on investment performance over the long term).

Past performance should not be an over-riding factor.

Perhaps the investment consultants can take a lead here in recommending a better design for DC investments. So far, the industry has not risen to this challenge. Obviously, improved financial education and advice would be helpful when people are being asked to provide more for themselves, and it is hoped that the authorities and investment firms will address this as soon as possible.

\section{Conclusion}

The way they are structured at present, DC pensions in the UK are likely to lead to enormous disappointment in years to come. Trustees are not yet generally providing schemes which enable 
members to structure optimal investment portfolios; members are not yet being educated sufficiently on appropriate contribution rates; investment houses have not yet devised dedicated DC investment products; and the authorities, firms or trustees have not provided sufficient investor education programmes to enable people to make well-informed decisions. (In the USA, mutual fund companies provide significant training in investment matters, often in the workplace, and the evidence suggests that this does lead to better investment decisions and a better understanding of the benefits of long-term investment in risky assets.) DC pensions in the UK are unlikely to provide sufficient income for retired people to live on and a majority may fall back on the state, thus undermining the Government's policy of reducing the burden of state pension payments by encouraging more private provision.

There is still a chance to structure the system better while it is in its early stages. It is hoped that this process can be accelerated and enable DC to provide better pensions in years to come than would be the case if left to creeping gradualism, without a clear focus on these issues. The longer contributions and investment design remain insufficient, the greater the likely pressure on the Exchequer in years to come.

Let's get DC provision right before it's too late.

\section{References}

1 Samwick, A. and Skinner, J. (1998) How Will Defined Contribution Pension Plans Affect Retirement Income, NBER Working Paper 6645, July.

2 H. M. Treasury (2001) Institutional Investment in the UK - A Review, March.

3 NAPF (1994, 1998, 1999) Annual Surveys.

4 Sefton, J. (2001) The Demand for Personal Pensions and Pension Return Guarantees, NIESR/INQUIRE Working Paper, January.

5 Turner, J. (2001) The Design of Rate of Return Guarantees for Defined Contribution Plans, AARP March.

6 Blake, D. (2000) 'Does It Matter What Kind of Pension Scheme You Have?', Economic Journal, Vol. 110, No. 461, pp. F46-F81 February.

7 Blake, D. (2001) 'PensionMetrics: Stochastic Pension Plan Design and Value-at-Risk during the Accumulation Phase', Pensions Institute, May.

8 Watson Wyatt (2000) Pension Plan Design Survey. 